\title{
Enseñar la infección microbiana con otro enfoque: innovación docente en la asignatura de Biología de primer curso del Grado en Farmacia
}

\author{
Ma de LOURDES MORENO AMADOR \\ Departamento de Microbiología y Parasitología \\ Facultad de Farmacia \\ Universidad de Sevilla \\ Imoreno@us.es \\ ORCID: https://orcid.org/0000-0002-7490-2037 \\ D.0.I.: http://dx.doi.org/10.12795/JDU.2018.i01.59 \\ Pp.: 1053-1069
}

\section{Resumen}

El trabajo que se presenta está basado en la experiencia docente llevada a cabo en la asignatura Biología de primer curso del Grado en Farmacia. La realización del ciclo de mejora ha pretendido cambiar el enfoque de la práctica docente clásica de tipo expositiva por una que concibe el aprendizaje crítico natural como estrategia didáctica. La propuesta docente ha abordado el tema dedicado a las infecciones en sus dimensiones conceptual y procedimental, abogando por un mayor equilibrio entre las competencias exigidas, los objetivos establecidos y la metodología de enseñanza-aprendizaje propuesta. El objetivo principal ha sido la participación activa del alumnado como actor principal en su proceso de aprendizaje. 
Palabras clave: Innovación Docente, Ciclo de Mejora Docente, Experimentación docente universitaria, Biología, Grado en Farmacia.

\section{Breve descripción del contexto}

La asignatura Biología sobre la que se ha realizado el ciclo de mejora docente (CMD) es de 10 Curso del Grado en Farmacia y es de carácter obligatorio. Es una asignatura interdepartamental que comprende 6 ECTS distribuidos en 4 teóricos 0,5 teórico-prácticos y 1,5 para prácticas de laboratorio. En ella participamos 12 profesores diferentes y tanto la estructura de las clases como el sistema de evaluación es muy poco flexible, hay examen y guiones teóricos comunes para todos los grupos. El grupo está integrado por 67 alumnos, de los cuales asisten con regularidad el $60 \%$. El número de alumnos repetidores es 20.

El tema seleccionado para el CMD es el correspondiente a las enfermedades infecciosas, que tiene mucha trascendencia para un farmacéutico, en cualquiera de las futuras vertientes donde ejerza la profesión. En lo que respecta a los conocimientos previos de este tema por parte de los alumnos suele haber bastante diversidad. Cabe destacar la repercusión de este tema en las restantes asignaturas relacionadas con Microbiología, ya que es el nexo de unión con la asignatura de Microbiología de 2o curso y con Microbiología Clínica de 5o curso.

En cuanto a los recursos disponibles, contamos con un aula antigua, con bancas fijas corridas y pizarra convencional, además de tener un proyector para exponer digitalmente. La mesa del profesor está situada en altura con respecto a las bancas de los alumnos. En lo que respecta a la programación, el CMD se desarrolló en 6 sesiones, con una duración de 3 días a la semana (martes, miércoles y jueves), 1 hora al día y en horario de 16:00-17:00 horas. Mi experiencia docente en esta asignatura comprende estos dos últimos años. He impartido docencia en Microbiología, Ampliación de Microbiología y en clases prácticas de todas las asignaturas que imparte mi Departamento en el Grado en Farmacia y, anteriormente, en la Licenciatura. 


\section{Diseño previo del Ciclo de Mejora Docente}

En el diseño de este CMD para la asignatura de Biología se ha apostado por una metodología que aboga por un aprendizaje crítico natural, en el cual se mantiene la atención del estudiante y se despierta interés en éste para seguir aprendiendo fuera del aula (Bain, 2007). Para ello, se ha reducido el tiempo dedicado a la exposición teórica clásica de contenidos por parte del docente, sin participación del alumnado, hacia una clase más dinámica, donde se intercala la enseñanza transmisiva de ciertos contenidos por parte del docente pero de menor duración, con actividades en clase en las que los alumnos tienen el papel protagonista. De esta manera, el docente actúa como facilitador de un proceso de aprendizaje, desarrollado según un paradigma de enseñanza centrado en el estudiante. Algunas investigaciones previas han demostrado la eficacia de este modelo educativo (Pierce \& Fox 2012; Flumerfelt \& Green 2013).

Como se observa en la Figura 1, el modelo metodológico posible que se ha diseñado para el CMD se basa en la exploración de ideas previas del alumno (E) que se ha llevado a cabo mediante la realización de un cuestionario inicial, seguido del planteamiento por parte del docente de un problema (Pr). El propósito del mismo era poder debatir con los alumnos al respecto, con el objetivo de engancharlos con algo que les resulte de interés. Después se intercala la exposición de conceptos teóricos (T) y prácti$\cos (\mathbf{P})$ impartidos por la docente, concebida aquella como un contraste de ideas. Complementariamente, los alumnos llevan a cabo actividades de contraste (A) encaminadas a trabajar en grupo, en las cuales ellos describen y debaten sus ideas sobre los contenidos propuestos. Finalmente, los alumnos cumplimentaron de nuevo el cuestionario inicial (c). Las actividades enmarcadas en cuadros corresponden a los alumnos y aquellas en círculos las lidera la docente. 


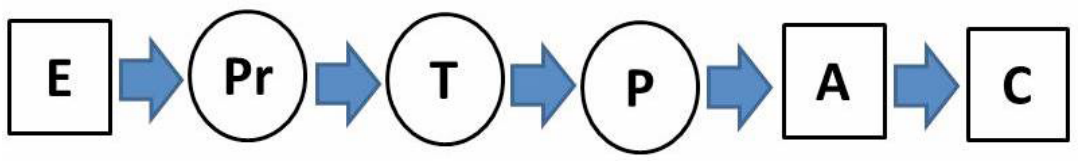

Figura 1. Esquema del modelo metodológico posible aplicado en el CMD de la asignatura teórica de Biología del Grado en Farmacia.

\section{Mapa de contenidos}

El uso del mapa conceptual fue un recurso desarrollado por Novak \& Gowin (1988), dentro del marco de un programa denominado "Aprender a Aprender", para promover el aprendizaje significativo, teoría fundamentada en la psicología cognoscitiva de Ausubel et al. (1976). En esta teoría se defiende el aprendizaje por recepción donde el profesor estructura los contenidos y las actividades a realizar para que los conocimientos sean significativos para los estudiantes.

En este CMD se ha diseñado un mapa de contenidos correspondiente a las enfermedades infecciosas que se ilustra en la Figura 2. Es una herramienta útil para la planificación de las clases, dado que facilita la visualización de las interacciones entre los contenidos que deberían aprender los alumnos. Se integran tanto los contenidos conceptuales como los procedimentales que identifican el qué, el quién, el cómo y el para quién, es decir, los contenidos adquieren un significado profundo cuando se encuentran enmarcados y relacionados en una "red de conceptos". En la Figura 2 las flechas indican que los conceptos están relacionados entre sí. Los conceptos principales aparecen representados en amarillo, son elementos indispensables para que pueda darse la infección. Los contenidos conceptuales se indican en cuadros azules y en el caso del cuadro rojo representa el contenido procedimental. 


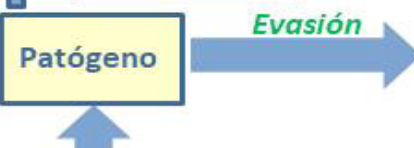

Tipos

1. Virus

2. Bacterias

3. Hongos

4. Protozoos

5. Parásitos

\section{Contenido conceptual}

\section{Conceptos principales}

Contenido procedimental
Pruebas

complementarias

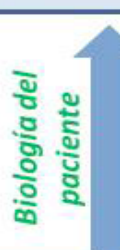

ENFERMEDAD INFECCIOSA

1. Adhesión

2. Colonización

3. Penetración

4. Evasión

5. Diseminación

6. Salida y transmisión

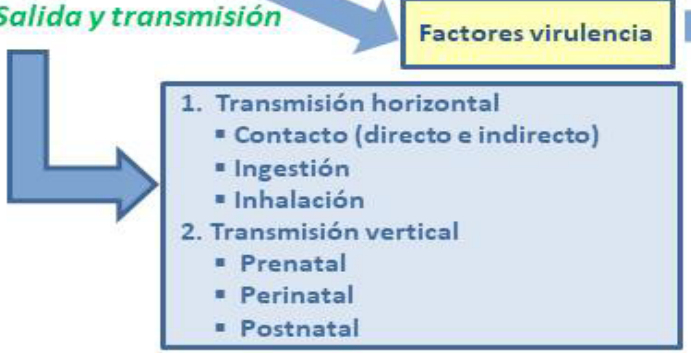

1. Toxinas

2. Enzimas

3. Otras sustancias

\section{Enzimas líticas}

2. Quemaduras

4. Ulceras

. Picaduras

6. Endocitosis

Figura 2. Mapa de contenidos correspondiente a las enfermedades infecciosas de la asignatura de Biología del Grado en Farmacia.

Jornadas de Formación e Innovación Docente del Profesorado | № 1 (2018)

cc (i) E $\odot$ Esta obra se distribuye con la licencia Creative Commons

cc) (i) $\Theta$ Reconocimiento-NoComercial-SinObraDerivada

Internacional (CC BY-NC-ND 4.0.) 


\section{Cuestionario inicial-final}

Para conocer los modelos mentales de los estudiantes se suelen utilizar cuestionarios, entrevistas, la observación y las producciones, combinándolas de forma adecuada. Los cuestionarios constituyen el instrumento más adecuado cuando se inician procesos de innovación docente, ya que permiten recoger respuestas por escrito de todos los estudiantes a la vez y realizar un análisis sistémico (Porlán, 2017). El cuestionario de exploración de ideas previas que se utilizó en el CMD se ha elaborado especificamente respecto a los contenidos evaluables tanto teóricos como reflexivos. Este cuestionario estuvo constituido por las cinco preguntas relacionadas con el concepto de "infección", redactadas con un lenguaje coloquial. En primer lugar se afirmaba: "Seguro que alguna vez en tu vida has tenido una infección" y cuestionaba si conocían el significado de tener una infección y que explicaran en qué consistía. A continuación se formuló una pregunta relacionada con el concepto de patógeno oportunista, instando a los alumnos a poner ejemplos de los que conocieran. Para ahondar en el concepto de vías de transmisión de enfermedades infecciosas se formuló: “¿Las enfermedades infecciosas ¿Cómo se cogen? Pon ejemplos" y de forma específica se cuestionó un concepto muy importante en las enfermedades infecciosas como es la transmisión vertical, preguntándoles en qué consistía esta transmisión. Finalmente se preguntó sobre la comparación toxina y patógeno, dado que es un concepto que suele conducir a confusión.

\section{Aplicación del Ciclo de Mejora Docente}

En este apartado procedo a realizar un relato resumido de las sesiones. El ciclo comienza con el planteamiento de la siguiente pregunta clave: ¿De qué consideráis que mueren principalmente las personas en el siglo XXI? ¿Qué lugar ocupan las enfermedades infecciosas como causa de 
muerte? El objetivo era enganchar al estudiante desde el inicio de la clase con algo que le resultara de interés, pero estrechamente relacionado con las implicaciones biológicas de la enfermedad infecciosa. Formular esta pregunta requirió mucho tiempo por mi parte dado que, a pesar de haber elaborado el mapa de contenidos del tema previamente y tener claros los conceptos conceptuales y procedimentales para abordar, idear una pregunta atractiva a la vez que centrada en el tema fue para mí un gran retro. Esta actividad requirió más tiempo del previsto dado que los alumnos sorprendentemente comenzaron a discutir abiertamente y las reflexiones tuvieron diferente complejidad. En segundo lugar, para continuar con el desarrollo del CMD, repartí un cuestionario inicial que debía rellenar el alumnado. Éstos se muestran algo asombrados al tener que responder sobre cuestiones no tratadas con anterioridad, pero una vez explicado su sentido, responden sin limitación y con cierta soltura, dado que se dan cuenta del lenguaje coloquial de las cuestiones y de la naturaleza poco teórica de éstas. En el resto de la sesión me dio la impresión de que estuvieron más atentos los alumnos al ver que algunos de los conceptos que estaba explicando estaban relacionados con lo que había preguntado en el cuestionario. Esta actividad se demoró más tiempo de lo esperado. Algunos alumnos me solicitaron tiempo para pensar y redactar sus opiniones y consideré que, dado que mi interés era conocer lo que sabían sobre el tema, debía dejarles lo necesario para ello. Esto supuso un retraso generalizado en el resto de la clase. A continuación se fue desarrollando el resto de actividades programadas, cuya dinámica puede resumirse en las siguientes acciones: grupo dirigido por la docente, sobre todo en la introducción de los temas; trabajo parcialmente dirigido por la docente, por ejemplo, en el acompañamiento de ejercicios; trabajo en grupos con una forma de tutoría en la que los estudiantes más avanzados apoyan a los demás y en la que los estudiantes resuelven una actividad juntos y trabajo individual 
en el que el material y el estudiante dirigen el proceso independientemente.

La introducción del tema me resultó especialmente fácil dado que utilicé el mapa de contenidos que había diseñado previamente. Pese a ser una tarea tan asequible para la docente, nunca me había planteado realizarla. Los alumnos me pidieron que se lo subiera a la plataforma por su claridad. A continuación realicé una exposición teórica de los contenidos previstos en el tema, haciendo especial hincapié en aquellos relacionados con las preguntas del cuestionario, teniendo así su primer contraste de información.

El 2o- día, el CMD se inicia con una exposición de las principales conclusiones obtenidas en los cuestionarios individuales que rellenaron los alumnos en la clase anterior, haciendo énfasis en los errores más frecuentes y resaltando puntos fuertes e importantes. Dedicamos 10 minutos a hacer una recopilación de lo visto en la sesión anterior, incidiendo y destacando aquellos aspectos fundamentales sobre los que tendrían que prestar especial atención cuando estudiasen las cuestiones vistas en la sesión. Después se comienza una actividad por grupos para que contrasten información sobre conocimientos derivados del concepto de infección. Se solicita que hagan una relación de cuatro patógenos oportunistas y otros cuatro microorganismos pertenecientes a la microbiota normal. Comienzan a discutir en los grupos sobre sus planteamientos. Yo voy aprovechando para escucharles e ir comentando, según el interés y/o complejidad de las cuestiones, en el propio grupo, o al conjunto de la clase si son temas de interés general. A continuación hice una explicación teórica de los conceptos del tema, desarrollando el concepto de concepto de salud y enfermedad y describiendo la clasificación internacional de las enfermedades, hilando asimismo con el concepto de patógeno oportunista que se preguntó en el cuestionario inicial, con el objetivo de contrastar y/o ampliar la información sobre el tema trabajada anteriormente. 
El tercer día del CMD se inicia con un breve resumen del contenido impartido en la clase anterior relativo a la clasificación internacional de las enfermedades. Se continúa con una actividad por grupos para que contrasten información sobre conocimientos derivados del concepto de infección, en la cual deben elaborar una lista de las etapas del proceso infeccioso. Deberían elegir a un portavoz que sería quien finalmente transmitiría al grupo clase el trabajo realizado por parte de su equipo. Por último, hice una explicación teórica de las etapas del proceso infeccioso con ayuda de la lista que habían elaborado por grupos.

El siguiente día de implementación del ciclo de mejora comienza con el breve resumen del contenido impartido en la clase anterior relativo a las etapas del proceso infeccioso, dado que transcurre un fin de semana entre la 3 a y 4a clase y los alumnos llegan desorientados de lo que se impartió en la clase anterior. A continuación se realiza una actividad por grupos para contrastar información sobre las vías de transmisión de las infecciones conocidas por los alumnos. Al final de esta clase me sentí especialmente agobiada por el tiempo. Tenía que terminar el temario, pasar la encuesta final y hacer el cuestionario de opinión del alumnado sobre la actuación docente del profesorado de la Universidad.

El 5o día del CMD comienza con el breve resumen del contenido impartido en la clase anterior relativa a las vías de transmisión de las enfermedades. A continuación se realiza una actividad por grupos para que contrasten información sobre los conocimientos que tienen de las enfermedades que se transmiten por vectores y las diferencias con respecto al concepto de zoonosis. Los alumnos supieron identificar rápidamente la diferencia en el concepto de zoonosis con respecto a las enfermedades transmitidas por vectores y los ejemplos surgieron de forma rápida. Después se llevó a cabo una explicación por parte de la profesora de estos dos conceptos del tema, que sirvió a los alumnos para contrastar y/o ampliar la información 
sobre el tema trabajado anteriormente en grupos. Esta actividad se prorrogó más aprovechando el tiempo no dedicado a la actividad grupal previa. Hice especial énfasis en la diferenciación de dos conceptos que generalmente suelen confundir los alumnos e incluso les invité a que discernieran algunos de los ejemplos que habían trabajado en grupo.

El último día transcurrió nuevamente con el inicio de un breve resumen del contenido impartido en la clase anterior relativa a los conceptos de zoonosis y enfermedad transmitida por vectores. A continuación los alumnos de forma grupal buscaron información sobre el concepto de toxina y recabaron ejemplos de infecciones donde éstas están involucradas. Se dispersaron los alumnos en esta actividad porque el concepto de toxina lo asocian a tóxico y no a una sustancia producida por un microorganismo. A su vez, estaban nerviosos porque les había comentado que hablaría al final de la clase del formato de examen y demás cuestiones. Seguimos adelante con una explicación que duró menos de lo previsto dado que necesitaba finalizar el temario. Por último, los alumnos rellenaron el mismo cuestionario formulado el primer día de inicio del CMD basado en 5 preguntas y de forma individual. Los alumnos rellenaron con satisfacción las preguntas e incluso querían más tiempo para hacerlo mejor, dado que los incentivé diciéndoles que si había diferencias en su escala de aprendizaje pues les subiría la nota final. Esta actividad se prolongó más de lo previsto y así di por concluido el ciclo de mejora docente.

\section{Evaluación del aprendizaje de los estudiantes}

En lo que respecta a la evaluación, se espera que el alumno haya adquirido mediante un aprendizaje autónomo y/o cooperativo los conocimientos necesarios y, además, desarrollar y entrenar las competencias previstas en el programa de la materia, gracias a una reflexión profunda y a una construcción activa del aprendizaje (Prieto, 2006). Las escaleras de aprendizaje dan pautas visuales sobre el 
proceso de aprendizaje de cada estudiante en cada materia. Así, facilitan una evaluación y un apoyo individual continuo a largo plazo. De esta manera, los docentes se liberan mucho de su tarea tradicional de tratar de controlar los procesos de aprendizaje desde el frente del aula (Müller et al., 2015). Además, las escaleras de aprendizaje guían al estudiante en su trabajo, mostrándole su avance al terminar un tema o un área de aprendizaje. Son herramientas que detectan dinámicas en el proceso, saltos o desaceleraciones. Como los estudiantes documentan su propio avance en las escaleras de aprendizaje, ellos mismos pueden darse cuenta del proceso y reflexionarlo.

Para la evaluación del estudiante hay que establecer perfectamente los criterios y conocer sus inquietudes y formas de pensar y razonar. Para ello, se realizaron y analizaron los cuestionarios iniciales y finales. En primer lugar, se analizaron los resultados del cuestionario inicial, identificando los diferentes modelos de pensamiento, su grado de complejidad y su acercamiento a la realidad. En segundo lugar, se analizaron los resultados del cuestionario final de todos los alumnos, identificando aquellos modelos que habían aparecido en el cuestionario inicial, así como aquellos posibles nuevos modelos. Finalmente, se agruparon las respuestas de los alumnos dentro de cada modelo en porcentajes y se representaron los resultados en escalera de aprendizaje tanto de forma individualizada por pregunta como de forma generalizada del conjunto de respuestas por alumno.

La evaluación me ha parecido un proceso muy complejo para el profesor al exigir mucho tiempo y trabajo para poder conocer bien al estudiante y así detectar sus dificultades, pudiendo solucionar aquellos problemas que no les permiten aprender. Los modelos de pensamiento identificados fueron los siguientes: A, Conocimientos avanzados e ideas precisas; $\mathbf{B}$, Conocimientos medios, pero no pone ejemplos; C, Conocimientos básicos e ideas generales pero confunde algunos de ellos y $\mathbf{D}$, Sin apenas conocimientos sobre la pregunta formulada. 
Se han analizado un total de 39 cuestionarios iniciales y 42 cuestionarios finales. En la Figura 3 se representan los resultados globales obtenidos de los cuestionarios iniciales de los alumnos, el 52,3\% de ellos no tenía conocimiento sobre las preguntas formuladas en el cuestionario inicial, situándose en el nivel D y un 30,8\% se situó en el nivel C ya que poseían conocimientos básicos e ideas generales, algunos de ellos confundidos. Es decir, el 83,1\% de los alumnos estaba categorizado en los modelos más bajos de conocimiento.

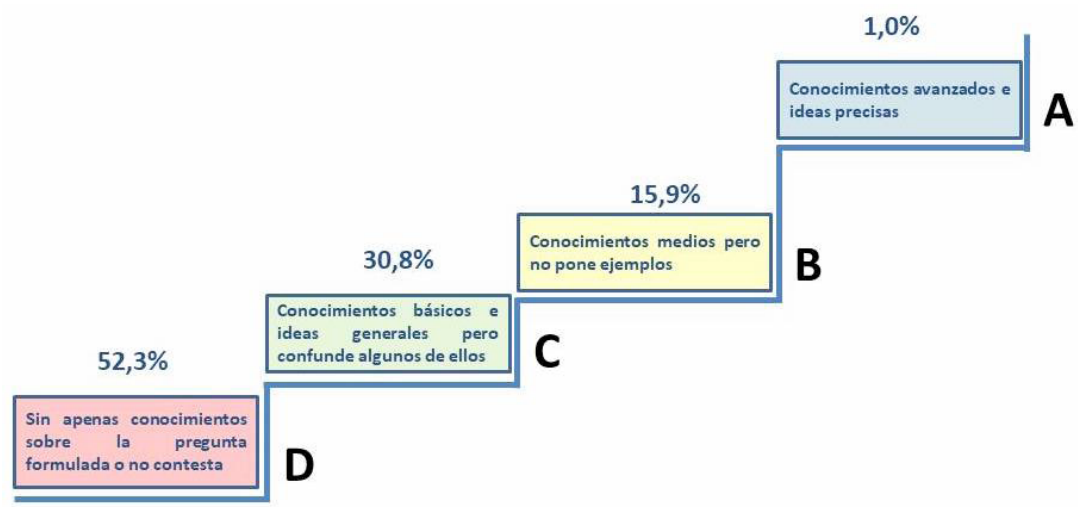

Figura 3. Representación en forma de escalera de aprendizaje de los resultados obtenidos tras la evaluación global de todas las preguntas del cuestionario inicial por cada alumno.

Si analizamos de forma individualizada las respuestas del cuestionario inicial por pregunta, tal y como se observa en la Figura 4, las preguntas 3 y 5 que versaban sobre el concepto de enfermedad infecciosa, toxina y patógeno fueron las que un mayor porcentaje de alumnos contestaron con modelos recogidos en las categorías B y C. Por el contrario, el $100 \%$ de alumnos desconocía por completo el concepto de transmisión vertical cuestionado en la pregunta 4, incluyéndose todos ellos en el modelo D. 

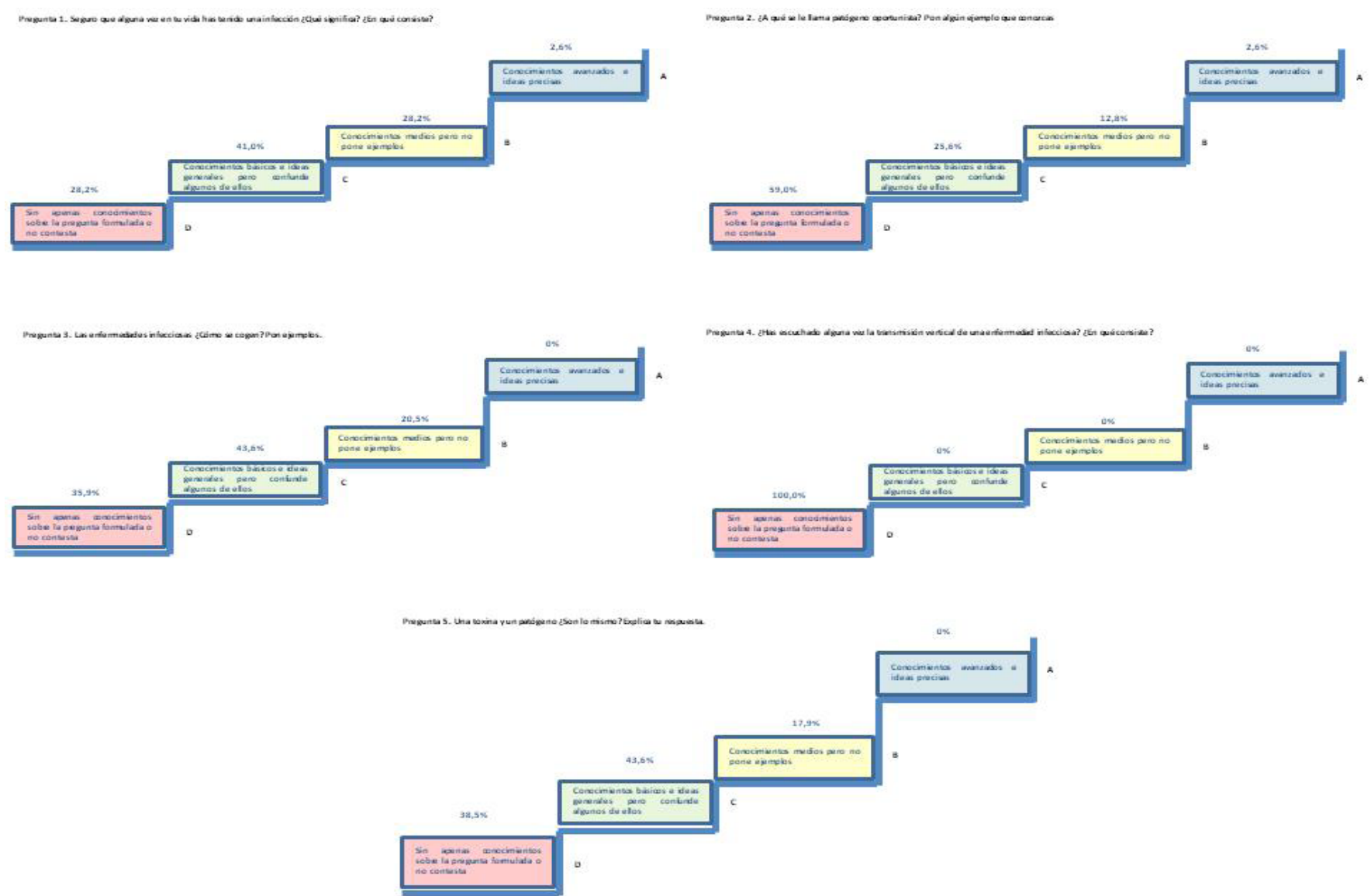

Figura 4. Representación en forma de escalera de aprendizaje de los resultados obtenidos tras la evaluación individual de cada una de las preguntas que conforman el cuestionario inicial.

Jornadas de Formación e Innovación Docente del Profesorado | № 1 (2018)

cC (i) $\odot$ Esta obra se distribuye con la licencia Creative Commons

(c) $)()_{\mathrm{EY}} \mathrm{NO}_{\mathrm{ND}}$ Reconocimiento-NoComercial-SinObraDerivada

Internacional (CC BY-NC-ND 4.0.) 
En lo que respecta a la evaluación del aprendizaje, el alumno debe haber adquirido mediante aprendizaje autónomo y/o cooperativo, los conocimientos necesarios además de desarrollar y entrenar las competencias previstas en el programa de la asignatura de Biología gracias al diseño de actividades y herramientas. Los resultados obtenidos tras el análisis global de los cuestionarios finales (Figura 5) muestran que se redujo un $37,1 \%$ el número de alumnos situados en el nivel D sin conocimientos sobre las cuestiones planteadas en el cuestionario así como se duplicó el número de alumnos de los niveles $\mathrm{A}$ y $\mathrm{B}$ y, especialmente, adquirieron el nivel A un 15,2\% más de alumnos.

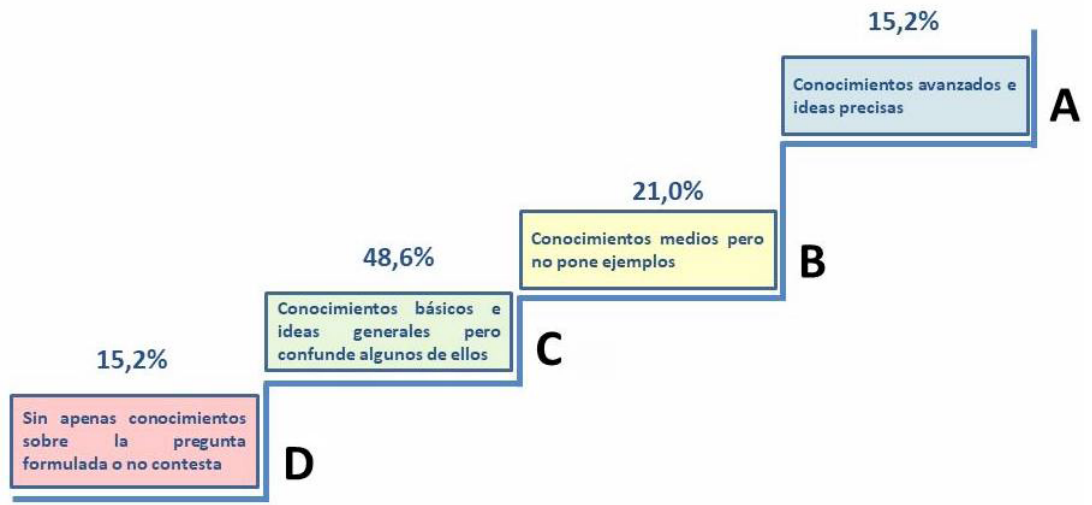

Figura 5. Representación en forma de escalera de aprendizaje de los resultados obtenidos tras evaluación global de todas las preguntas del cuestionario final por cada alumno.

El análisis individualizado de las preguntas del cuestionario final indicó que la pregunta en la que el mayor porcentaje de alumnos adquirieron nivel A fue la pregunta 5. La pregunta 4 fue la que presentó mayor grado de evolución positiva dado que se redujo un $81 \%$ el número de alumnos del nivel $D$ que no tenían conocimientos y se consiguió un $16,7 \%$ de alumnos con nivel de conocimiento A. Sin embargo, con respecto a la pregunta primera se observa que aunque en hubo un incremento del porcentaje de alumnos que adquirieron el nivel máximo de 
competencias planteadas, el grupo mayoritario de alumnos (que representaron un 66,7\%) no supieron aplicar los conceptos que se desarrollaron en las explicaciones con la pregunta cuestionada. En este aspecto, en lo que respecta a mi actividad docente, quizás no les supe trasladar este mensaje acorde al sentido práctico de la misma. La pregunta presentaba un texto bastante informal donde se pretendía que el alumno describiera la infección como un estado contrario a la salud, donde esbozara algunas de las fases de la infección y expusiera los signos y sintomas de una infección general. Si esta pregunta quizás la hubiese hilado más con el mapa de contenidos hubiese tenido más éxito. Con respecto a la pregunta 2, ha habido muchos alumnos que han pasado del nivel $D$ al $C$ y muchos del $C$ al B y lo más importante al A. Es quizás la pregunta que conceptualmente era la más simple y la "supuestamente" más conocida por ellos en cuanto a definición. El hecho de que muchos de ellos no pusieron ejemplos fue la limitación a la hora de categorizar en el nivel A. La pregunta 3 que cuestionaba el concepto de vías de transmisión fue muy curiosa. Hubo alumnos cuyas respuestas estaban categorizadas en C o B pero sabía poner ejemplos. Es decir, no sabían contestar bien los tipos de transmisiones o confundían las vías pero ponían ejemplos concretos explicados en la clase y los asociaban bien a la vía. En esta pregunta he podido observar cómo les llama la atención a los alumnos las imágenes de determinadas enfermedades y las explicaciones sobre el origen de la transmisión de enfermedades conocidas por ellos a través de los medios de comunicación de las cuáles adquirieron información en clase.

\section{Evaluación del Ciclo de Mejora Docente}

La experiencia de este CMD va a repercutir en mi práctica docente futura ya que voy a intentar instaurarlo en todas las asignaturas donde imparto docencia y en especial 
en los temas que resultan más tediosos a los alumnos con el objetivo de poco a poco ampliarlo a más temas de la asignatura de Biología sobre la que he realizado este CMD. De forma general, lo que más se ha alejado del diseño previo ha sido el tiempo dedicado a las actividades en grupo que se habían programado para 15 minutos cada día del CMD y en ciertas ocasiones se han dilato más. Esto ha generado un retraso en el programa que ha supuesto recortar el número de actividades de los días finales (31 octubre y 6 noviembre). Cabe destacar también que se ha dilatado el tiempo en la realización de los cuestionarios ya que al repartir y recoger generalmente los alumnos suelen hablar y hay que poner orden y esto conlleva unos minutos de tardanza lo que ha conllevado un recorte en mi exposición teórica. La realización del cuestionario inicial me ha servido para descubrir los conocimientos previos de los que partían los alumnos sobre este tema. Personalmente considero que para el alumno también ha sido muy gratificante el cuestionario ya que cuando rellenaban el cuestionario final se les notaba con una actitud diferente contestando al ver que habían adquirido los conocimientos que se cuestionaban. Tras el cuestionario inicial, comentaron y detectaron los errores, contrastaron información con las explicaciones que les proporcioné y asimilaron información. El transcurso del CMD ha sido en general muy gratificante para mí. Considero que los alumnos estaban muy participativos, ilusionados y en general lo que más me ha sorprendido positivamente es la actitud de éstos en el debate abierto en clase. Realmente creo que han sido ellos el foco de atención de la clase y he tenido la sensación de que se han divertido y aprendido mucho más que en cursos anteriores en que he utilizado el método de enseñanza tradicional basado en la transmisión. 


\section{Referencias bibliográficas}

Ausubel, D.; Novack, J.D. y Hanesian, H. (1976). Psicología educativa desde un punto de vista cognoscitivo. México, D. F.: Trillas.

Bain, K. (2007). Lo que hacen los mejores profesores universitarios. Valencia: Publicaciones de la Universidad de Valencia.

Flumerfelt, S \& Green, G. (2013). Using learn in the flipped classroom for at risk students. Educational Technology \& Society 16 (1), 356-366.

Müller, T.; Lichtinger U. y Girg, R. (2015). The MultiGradeMultiLevel-Methodology and its Global Significance. Ladders of Learning-Scientific Horizons-Teacher Education. Immenhausen near Kassel: Prolog

Novak, J.D y Gowin, D.B. (1988). Aprender a aprender. Barcelona: Martínez Roca.

Pierce, R \& Fox, J. (2012). Vodcasts and active-learning exercises in a "flipped classroom" model of a renal pharmacotherapy module. American Journal of Pharmaceutical Education 76, Article 196.

Porlán, R. (Coord..) (2017). Enseñanza Universitaria. Cómo mejorarla. Madrid: Morata/Servicio de Publicaciones de la Universidad de Sevilla.

Jornadas de Formación e Innovación Docente del Profesorado | № 1 (2018) Esta obra se distribuye con la licencia Creative Commons 